these changes will outweigh the disadvantages. No doubt readers will appreciate the preselection of articles which separate publication makes possible. To set against this may be a slight increase of the time-lag before publication and the possibility that important articles will not reach as wide a readership as they deserve. Although it is known that the British society would like to see a wider integration of scientific journals on a European basis, the splitting of the journals is not directly related to developments of that kind.

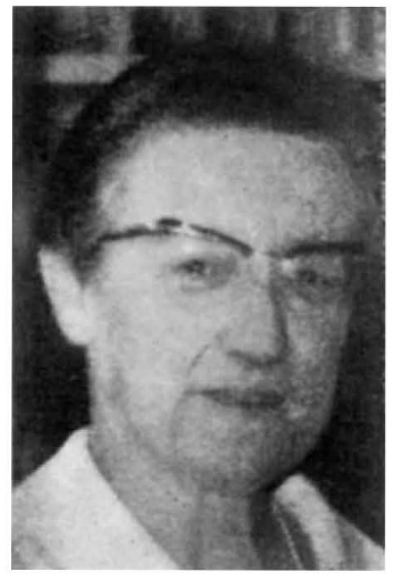

The society has also in the past few weeks lost through retirement Dr A. C. Stickland, editor and deputy secretary. Dr Stickland joined the staff of the Physical Society twenty years ago. She has been appointed managing editor of the Annals of the International Years of the Quiet Sun under the auspices of the International Council of Scientific Unions.

\section{Making the Most of Manpower}

A PouICY conference on highly qualified manpower held in September 1966 is agreed to have raised more problems than it solved, but the report just published by the Organization for Economic Co-operation and Development (OECD), which ran the conference, includes an impressive list of recommendations.

Means of adapting educational systems to meet economic needs were discussed, together with the use of manpower by employers. In an age when science and technology are expanding quickly, education and training are vital and must be continued throughout the working life of each individual if accumulated know. ledge is not to become obsolete-this is a familiar theme of OECD. The report lists five areas in which research must be done if the problems involved are to be pinned down. These cover improvement and standardization of statistics of personnel and the reasons why different people chose various academic subjects, training and jobs. Only by following individuals through various stages in their careers will the important influences be discovered.

The conference recommends to the member countries that they should develop systematic policies for the training and efficient employment of highly quali. fied manpower to meet their economic needs. The aim should be to provide education at school, university and in the job which adds up to a coherent whole for each individual, as well as providing a complete information service on employment situations and possibilities so that the best use is made of qualified workers. National bodies would have to be set up to organize the required research and put results into effect. On an international level, OECD members were asked to continue the present work by referring back to the governments concerned. A further conference is proposed.

\section{Foot and Mouth Disease}

More than 21,000 animals have so far been slaughtered during the fastest moving epidemic of foot and mouth disease for nine years in Britain. The number slaughtered includes 7,614 cattle, 6,709 sheep and 7,335 pigs. There have been 87 separate outbreaks.

The causative agent is a spherical RNA virus, 22 millimicrons in diameter and designated sub-type $O 1$. Of the seven immunological types so far characterized, foot and mouth disease in Britain is usually attributable to the three types $O, A$ and $C$. There is no reason to believe that type $O 1$ is particularly virulent, and it has indeed occurred in several European countries during the past few years. The most recent alarming outbreak of the disease in Northumberland and Southampton in 1966 was also caused by type $O 1$.

The present outbreak was confirmed on October 25 at a farm near Oswestry in Shropshire, at a time when a large animal market was being held in the vicinity. There seems, however, to be no link between these cases and outbreaks in other counties. The veterinary service of the Ministry of Agriculture fears that there may well be an undisclosed source of infection in the area. It is possible, but unproved, that this epidemic is the result of infected meat imported from abroad. The virus can survive for days outside the animal body. It can be transmitted mechanically by direct contact from one animal to another, on cars or on the beaks and feathers of birds; transmission can also be airborne. As long as trade continues with infected countries, sporadic outbreaks in Britain will occur.

Another feature of the virus is its tendency to undergo antigenic variation. A vaccine incorporating the three types $O, A$ and $C$ is already being used on cattle in France, Belgium and Holland with encouraging results. The cost of such a vaccination scheme in Britain is said to be prohibitive - far greater than the cost of slaughter-and would, in any case, be impracticable. This is why there is a tendency to believe that charity begins abroad. Vaccine produced at the Animal Virus Research Institute, Pirbright, is exported to Turkey, Bulgaria and Greece. The institute also serves as the world reference laboratory for typing foot and mouth virus and for collecting information about epidemics.

\section{How to Deal with Oil}

"THE greatest peace-time operation ever mounted in the United Kingdom." This is how the recent report compiled by L. R. Beynon, British Petroleum Company, describes the efforts to fight the oil pollution after the Torrey Canyon incident. Far from being a mere account of events, the report includes the action which was taken and its effectiveness, and possible 
alternatives and considerations for future treatment of similar disasters.

The beginning of the operation was actually a series of failures. The rough weather did not make salvaging operations easy and pollution on this scale had never occurred before. The floating boom which had been intended to encircle the ship and reduce the spread of oil had not arrived. Furthermore, it was not until ten days after the ship had run aground that the air attacks were begun to fire some of the oil slicks and to destroy the remaining cargo. In all, $160,000 \mathrm{lb}$. of high explosives, 10,000 gallons of aviation kerosene, 3,000 gallons of napalm and several rockets were used to burn the oil in the ship and the surrounding area of sea.

Early attempts on the Cornish coast to fight the oil slicks which were building up on over a hundred miles of beaches are described as largely uncoordinated and haphazard. "Detergent was being sprayed or slopped from small boats with little effect and its application to polluted beaches and rocks was, in general, remarkably inefficient and wasteful." Detergent treatment without subsequent water washing added to the distressing situation instead of abating it, and booms which had been installed at Porthleven Harbour proved useless. It was not until troops had been drafted into the area and vast supplies of detergent were introduced that any encouraging results were seen.

One possible method for fighting oil pollution on the sea involves the use of vessels designed to skim the oil from the surface. Such vessels have been used in sheltered harbours but cannot be considered as sea going vessels. The report suggests that the problems of skimming oil off the sea might be reduced by the application of coagulants and floating absorbents; but the problem still remains of collecting the coagulated contaminant in open sea conditions. Another alternative is to sink the oil using granulated materials of high density. The sunken oil, however, could damage marine life and there is a danger that it would not be rendered permanently immobile and could repollute the water. The destruction of oil by burning on a damaged tanker is impracticable, the report says, and attempts to burn oil floating on the sea are inefficient. The only practical means of dispersing the oil is by the application of detergent: in all, about one million gallons were used to emulsify oil at sea in the case of the Torrey Canyon.

Several lessons were learned about operations on and close to shore. Booms were found to be effective in preventing the passage of oil only if exposed to sea conditions with currents of under two knots or waves less than a foot high. Where oil reaches appreciable thickness in harbours, sewage vehicles can be used to skim off the oil, or absorbent substances such as straw, ash and plastic materials can be used to absorb the oil. Oil stained harbours and estuary walls can be cleaned effectively by spraying with detergent and then hosing down with jets of water. The quickest method of cleaning a sandy beach involves the use of an agricultural rotary cultivator. This breaks up the oil and mixes it with sand, and detergent is then sprayed on.

For the future, the report recommends the building of tankers with high speed pumps to transfer the oil from a damaged tanker, some efficient means of mixing the sea water, oil and detergent after spraying the oil slicks and the development of cheaper, less toxic but effective detergents.

\section{Step Nearer to Space Stations}

\author{
from a Correspondent
}

IT is curiously appropriate that one of the space "spectaculars" marking the fiftieth anniversary of the Russian Revolution should have been a demonstration that a technique fundamental to building orbiting space stations has been mastered-that is, the automatic rendezvous and docking of two spacecraft. It is to that astonishingly practical analyst of the laws of space exploration, Tsiolkovsky - whose principal work was done in isolation and hardship in the later days of the Tsars-that is due the main credit for the space station concept-a combination of springboard to the stars and the most economic means of obtaining an extra-terrestrial observing platform. After the revolution, Tsiolkovsky received the recognition and applause he no longer sought, but his message is remembered. As the Russian space strategy emerges, it sometimes seems that Tsiolkovsky's ideas are the conceptual blueprint for it.

It may be months or longer before a space station exists in orbit, but this is probably now the Russian intention. Such a contraption could be of great value in its own right, both as a manned observatory for a wide range of surveys and for astronomy freed from the encumbrance of atmospheric instability. Several senior Russian scientists-at the Belgrade Astronautical Congress and elsewhere-have recently expressed unqualified enthusiasm for the observational possibilities. Equally, a space station could be used as a staging post for assembling the components of the substantial "spaceship" required for the manned leap to the Moon. The basic techniques are the same, and the smooth encounter, joining and separation of Cosmos 186 and 188 show these no longer pose insuperable problems. Similar manoeuvres will have to become routine and a considerably higher orbit achieved before a multi-component space station can be assembled.

But the Russian claim that the automatic link-up is the key technological advance in the present phase of space development seems justified.

In last week's encounter, Cosmos 186 was the "active" partner, and was subsequently recovered. Independent evidence indicates that Cosmos 186 and 188 were of Soyuz dimensions $(3 \times 9 \mathrm{~m})$ and can therefore carry a man, or even men. The active Cosmos 186 seen on television pictures was equipped with brief curved "wings", which suggests a certain degree of built-in aerodynamic control. Hints of such a development for the more complex manoeuvres of the future emerged in the remarks of an influential Soviet engineer at one of the technical sessions of the Belgrade meeting. It would obviously be more convenient if a returning cosmonaut could arrange to touch down near home rather than abroad, even if in future he will also be equipped to land in the sea.

\section{Quartz Mirror for Kitt Peak}

THE fusion of fifteen tons of quartz into a mirror blank takes the astronomical telescope at Kitt Peak National Observatory, Arizona, one step nearer completion, but there is still more than two years of optical work to be done on the mirror before it is ready for use. The General Electric Company of the USA made several attempts at fusion before successful treatment of the 158 inch mirror blank at $3,300^{\circ} \mathrm{F}$ in a specially 